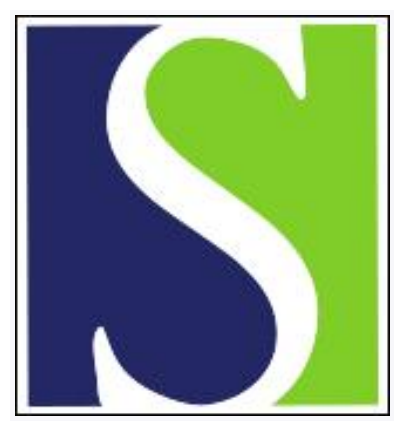

Scand J Work Environ Health 1976;2(1):54-63

https://doi.org/10.5271/sjweh.2831

Issue date: 1976

Angina pectoris, ECG findings and blood pressure of foundry workers in relation to carbon monoxide exposure.

by Hernberg S, Kärävä R, Koskela R-S, Luoma K

The following article refers to this text: 1989;15(4):245-264

Key terms: angina pectoris; blood pressure; carbon monoxide exposure; ECG finding; foundry work; foundry worker; prevalence study

This article in PubMed: www.ncbi.nlm.nih.gov/pubmed/968466 


\title{
Angina pectoris, ECG findings and blood pressure of foundry workers in relation to carbon monoxide exposure
}

\author{
by SVEN HERNBERG, M.D., RISTO KÄRÄVÄ, M.D., RIITTA-SISKO \\ IKOSKELA, M.Sc., and KALEVI LUOMA, B.Sc. ${ }^{1}$
}

\begin{abstract}
HERNBERG, S., KÄRÄVÄ, R., KOSKELA, R.-S. and LUOMA, K. Angina pectoris, ECG findings and blood pressure of foundry workers in relation to carbon monoxide exposure. Scand. j. work environ. \& health 2 (1976): suppl. 1, 54-63. A prevalence study on angina pectoris, ECG changes, and blood pressure was carried out with those 1,000 workers (response rate $93.1 \%$ ) with the longest exposure time (minimum 4.2 years) from a statistical sample of 20 foundries. The history of angina was obtained from a questionnaire recommended by the World Health Organization, and the ECGs were coded according to the Minnesota code. On the basis of measurements of the concentration of carbon monoxide $(\mathrm{CO})$ in the air, the workers were divided into three occupational exposure groups, one with definite $\mathrm{CO}$ exposure, one with slight or occasional $\mathrm{CO}$ exposure, and one without $\mathrm{CO}$ exposure. Allowance was also made for present and past smoking habits. All comparisons were made on an intrasiudy basis between the different subcategories. The prevalence of angina showed a clear dose-response relationship with regard to $\mathrm{CO}$ exposure from either occupation, smoking, or both, but no such trend was found for ECG findings suggestive of CHD. These results may suggest a greater sensitivity in detecting CHD on the part of the angina questionnaire. The systolic and diastolic blood pressures of CO exposed workers were slightly higher than those of other workers when age and smoking habits were taken into consideration. However, exposure to heat was intermixed with exposure to $\mathrm{CO}$. It could be shown that selection based on health had operated in the foundries. Hence, the prevalence found can be considered to be underestimates of the "true" occurrence of cardiac disorders. Nevertheless both angina and "coronary" ECG findings were more prevalent than in other methodologically comparable studies on the general population or industrial workers without toxic exposure.
\end{abstract}

Key words: foundry work, carbon monoxide exposure, angina pectoris, blood pressure, ECG findings, prevalence study.

Carbon monoxide (CO), heat, and strenuous physical work, or any combination of the three, are those environmental factors in foundry work that possibly relate to coronary heart disease (CHD). Any of

1 Department of Epidemiology and Biometry, Institute of Occupational Health, Helsinki, Finland.

Reprint requests to: Dr. Sven Hernberg, Institute of Occupational Health, Haartmaninkatu 1, FIN-00290 Helsinki 29, Finland. these factors may, in principle, contribute to the etiology of CHD, accelerate its progress, or provoke symptoms of an already existing disease.

Recent literature indicates that even comparatively low exposure to $\mathrm{CO}$ (a) causes atherosclerosis in laboratory animals, particularly when combined with a diet rich in saturated fats $(8,9,24)$; (b) decreases the arteriovenous difference in oxygen saturation in the heart muscle and also the myocardial oxygen consumption 
of laboratory animals and, concomitantly, increases coronary flow (1); (c) decreases exercise tolerance and worsens S-T segment depressions in patients with angina pectoris $(2,5,6)$; and (d) decreases also the exercise tolerance of ostensibly healthy humans (3). Thus experimental exposure to $\mathrm{CO}$ seems both to promote the development of $\mathrm{CHD}$ and to provoke symptoms of existing disease. In addition $\mathrm{CO}$ is now considered to be the most harmful CHD promoting factor in cigarette smoke (7). Hence most of smokers' well-known increased morbidity and mortality from $\mathrm{CHD}$ may be ascribable to continuous $\mathrm{CO}$ exposure. If so, also occupational exposure to $\mathrm{CO}$ should constitute a comparable risk.

The most likely effect of physical work and heat exposure is that of provoking symptoms of existing CHD. However, strenuous physical work is less common in foundries nowadays than before, and the moderate exercise which occurs should rather prevent than increase CHD. Similarly, heat exposure is sporadic, confined to a few occupations only, and is hence less important.

Thus exposure to $\mathrm{CO}$ seems to emerge as the most significant link between CHD and foundry workers. As reported elsewhere (23), quite high concentrations do occur in the furnace and casting areas of foundries, especially in iron foundries. Although exposure is intermittent, it may cause clearly elevated concentrations of carboxyhemoglobin (up to $20 \%$ ) in casters and furnacemen (23), and their exposure may well constitute a hazard.

\section{MATERIAL AND METHODS}

Of the 1,789 men working in the 20 foundries sampled (11) those 1,000 with the longest history of foundry work were asked to participate in the study, and 931 of them responded. Their minimum exposure time was 4.2 years (mean 17 years, SD 9 years), and their mean age was 44 years (SD 11).

Each subject filled out a questionnaire on, among other things, occupational history, earlier morbidity, and smoking habits. At the time of the survey, 460 (or $53 \%$ ) of the 861 men giving a useful smoking history were active smokers.
Their proportion varied between 50 and $68 \%$ in the different occupational groups. Present smokers formed $58 \%$ of the CO exposed groups as compared to 52 to $53 \%$ of the two other groups; this difference is, however, hardly of any practical significance. Only 150 men $(16 \%)$ had never smoked, and $252(31 \%)$ were exsmokers. Of the exsmokers only $4(1.6 \%)$ had given up smoking recently $(<1$ year). The mean duration of abstinence from smoking was 9.2 years (SD 7.4).

The history of chest pain was obtained with the Rose Cardiovascular Questionnaire (21), which was completed by the subject in advance and checked at the health examination. The replies to the standardized questions were interpreted as indicative of angina (a) if the subject reported chest pain when walking uphill or at an increased pace on level ground or already at a normal pace on level ground, (b) the pain caused him to stop or slow down, (c) if the pain disappeared within 10 min of rest, and (d) if the pain was localized substernally or simultaneously on the left side of the thorax and in the left arm. The angina was classified as mild if the pain appeared only when hurrying or walking uphill and as severe if it appeared already when walking at a normal pace on level ground. Other types of chest pain were not classified as angina.

Blood pressure was measured by a technician using an Elag Köln BE 107 apparatus with the subject in a sitting position. The recording was made after a 10- to 15-min rest; for practical reasons abstinence from smoking could not be required.

A $100 \times 100 \mathrm{~mm}$ chest radiograph (anterior-posterior and lateral projections) was obtained with a Philips Medio 200 apparatus with an Odelca Angular Camera. The radiographs were read in a standardized manner by an experienced roentgenologist, who did not know to which exposure category the subject belonged.

A 12-lead resting ECG was recorded with an Elema Mingograph 34. The ECGs had to be taken without a sufficient preceding period of rest, and eating could not be prohibited either, because the examination, which took place during the 
work shift, should interfere as little as possible with the normal work routine. Although this practice may have influenced the absolute number of abnormal findings, no systematic errors were introduced since the workers attended the examination in alphabetical order. The comparability of information was thus maintained.

The ECGs were recorded at a paper speed of $50 \mathrm{~mm} / \mathrm{s}$. They were coded according to the new version of the Minnesota code (21) by two trained technicians. The recordings were read independently and, if there were disagreements, the code was decided upon jointly. A cardiologist checked and made the final decisions in cases where pathological Q- or QSwaves (MC 1) were observed.

Using the results of the $\mathrm{CO}$ measurements made in the foundries (23), we classified the various foundry occupations into the following exposure groups: (a) regular CO exposure: casters and furnacemen (including sieve repairmen, scrapmen and chargers), and laborers assisting them; (b) occasional or slight $\mathrm{CO}$ exposure: fettlers (including knock-out men and flame cutters), truck drivers, crane operators, loader drivers, and laborers assisting them; (c) no CO exposure: floor molders (including molding shop workers), machine molders, coremakers (including slinger drivers), ingot casters, "other occupations" (i.e., patternmakers, wheelabrators, welders, turners, smiths, trimmers, inspectors, maintenance workers), and laborers assisting them. Because of (a) differences between foundries, (b) the workers' movements during the day, and (c) the fact that several workers had been in different jobs during their working history, this classification is somewhat inaccurate. Furthermore, in small foundries some of the $\mathrm{CO}$ formed and liberated during melting and casting may spread to areas classified as having no $\mathrm{CO}$ exposure.

The results of the carboxyhemoglobin measurements have been described elsewhere (23). According to them, $26 \%$ of the carboxyhemoglobin concentrations of nonsmoking furnacemen and casters exceeded $6 \%$ while as many as $71 \%$ of the smokers' values exceeded that concentration.

All of our comparisons were made between the different exposure categories. Although an external comparison group had been considered during the planning stage, the special character of foundry work made it impossible practically to find another occupational group available for examination and comparable in all other respects but $\mathrm{CO}$ exposure. Using internal comparison groups would dilute a possible association between $\mathrm{CHD}$ and $\mathrm{CO}$ exposure rather than produce a spurious one, because slight $\mathrm{CO}$ exposure probably occurs in at least some of the areas classified as "nonexposed."

\section{RESULTS}

\section{Blood pressure}

There were no great differences between the blood pressures of the various occupational groups. However, as can be seen from table 1, both the systolic and the diastolic pressure was the highest among the casters, and the diastolic but not the systolic pressure was higher among the furnacemen. Both groups are exposed to $\mathrm{CO}$, but also to heat radiation.

Table 1. Mean values and standard deviations (SD) of the systolic and diastolic blood pressures $(\mathrm{mm} \mathrm{Hg})$ in various occupational subgroups.

\begin{tabular}{lrrrrrr}
\hline & & \multicolumn{2}{c}{ Systolic pressure } & & \multicolumn{2}{c}{ Diastolic pressure } \\
\cline { 5 - 6 } Occupational group & $\mathrm{N}$ & Mean & SD & & Mean & SD \\
\hline Machine molders & & 147 & 18 & 83 & 14 \\
Other laborers & 173 & 148 & 20 & 84 & 14 \\
"Other occupations" & 30 & 148 & 19 & 16 & 83 & 14 \\
Floor molders & 151 & 149 & 20 & 83 & 14 \\
Fettlers & 90 & 150 & 19 & 82 & 14 \\
Coremakers & 211 & 151 & 20 & 87 & 15 \\
Furnacemen & 64 & 151 & 19 & 87 & 13 \\
Casters & 109 & 154 & & & & \\
\hline
\end{tabular}




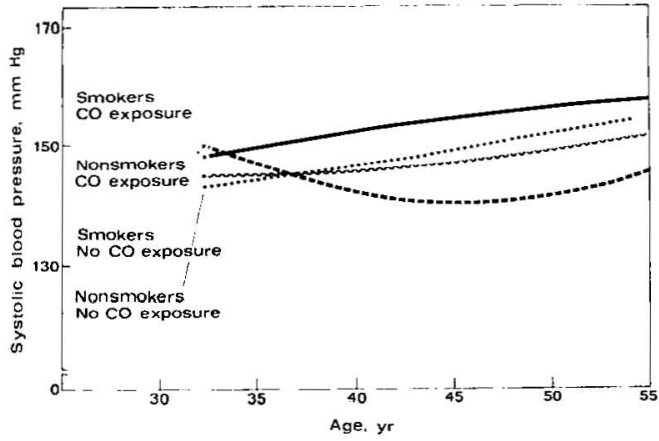

Fig. 1. Systolic blood pressure of foundry workers by carbon monoxide exposure and smoking category.

The difference between the systolic blood pressure of the casters and furnacemen and that of the groups with no CO exposure (molders, coremakers, "others") was probably not due to chance $(\mathrm{t}=2.49$, two-sided $\mathrm{p}<0.05)$. The same was true for the diastolic pressure $(t=$ 3.64 , two-sided $\mathrm{p}<0.001$ ). Even when all other groups were combined and compared with the furnacemen and casters, similar results were obtained (systolic pressure: $t=2.28$, two-sided $\mathrm{p}<0.05$; diastolic pressure: $\mathrm{t}=3.05$, two-sided $\mathrm{p}<0.01$ ).

When the combined effect of smoking and occupational $\mathrm{CO}$ exposure was studied, it appeared that nonexposed nonsmokers had the lowest systolic pressure; and $\mathrm{CO}$ exposed smokers and exsmokers, the highest one (figs. $1 \& 2$ ). The difference might have been due to chance, however $\left(\chi^{2}{ }_{(8)}=9.66, \quad \mathrm{p}>0.05\right)$. The blood pressure of $\mathrm{CO}$ exposed nonsmokers did not fit well into the general pattern. However their number was small $(\mathrm{N}=22)$, and the shape of the regression line may thus depend on chance. The diastolic pressures showed a more consistent pattern (fig. 2). The difference between the extreme groups was probably not due to chance $\left(\chi^{2}{ }_{(8)}=17.24\right.$, two-sided $\left.\mathrm{p}<0.05\right)$, but no other differences were statistically significant. In these comparisons both exsmokers and those with occasional or slight $\mathrm{CO}$ exposure have been omitted.

\section{Angina pectoris}

The prevalence of angina increased with

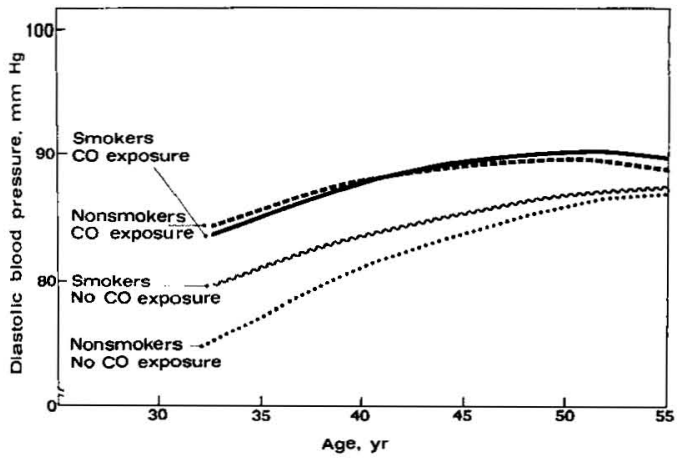

Fig. 2. Diastolic blood pressure of foundry workers by carbon monoxide exposure and smoking category.

age, as expected. In all, 127 men gave a history of typical angina according to the criteria set. Table 2 shows that the lowest prevalence occurred in nonsmokers not exposed to $\mathrm{CO}$, and the highest in exposed smokers. The other groups showed intermediate results.

The significance of the group differences was tested with the Mantel-Haenszel test (15), and the results are shown in table 3 . The highest rate ratio was obtained when the group with neither exposure was compared to that with both exposures. The effect of occupational $\mathrm{CO}$ exposure alone or of smoking alone was evident when groups with one of these

Table 2. Age-standardized prevalences of angina according to occupational carbon monoxide (CO) exposure and smoking habits.

\begin{tabular}{|c|c|c|}
\hline Exposure group & N & $\begin{array}{l}\text { Prevalence } \\
(\%)\end{array}$ \\
\hline \multicolumn{3}{|l|}{ Nonsmokers } \\
\hline \multirow{2}{*}{$\begin{array}{l}\text { No CO exposure (A) } \\
\text { CO exposure or occasion- } \\
\text { al CO exposure (B) }\end{array}$} & 79 & 2 \\
\hline & 71 & 13 \\
\hline \multicolumn{3}{|l|}{ Exsmokers } \\
\hline $\begin{array}{l}\text { No CO exposure (C) } \\
\text { Occasional CO }\end{array}$ & 138 & 13 \\
\hline exposure (D) & 68 & 10 \\
\hline CO exposure (E) & 46 & 15 \\
\hline \multicolumn{3}{|l|}{ Smokers } \\
\hline No $\mathrm{CO}$ exposure $(\mathrm{F})$ & 236 & 15 \\
\hline Occasional $\mathrm{CO}$ & & \\
\hline $\begin{array}{l}\text { exposure }(G) \\
\text { CO exposure }(H)\end{array}$ & 128 & 18 \\
\hline $\mathrm{CO}$ exposure $(\mathrm{H})$ & 95 & 19 \\
\hline Total & 861 & 14 \\
\hline
\end{tabular}


Table 3. Significances of the effects of smoking and occupational carbon monoxide (CO) exposure upon the prevalence of angina. The number of subjects in each group can be found in table 2 .

\begin{tabular}{|c|c|c|c|}
\hline Exposure categories & Rate ratio & $\chi^{2}(1)$ & $\mathbf{P}$ \\
\hline \multicolumn{4}{|l|}{ Effect of CO only } \\
\hline $\begin{array}{l}\text { No CO, nonsmokers (A) vs. CO or occasional CO, } \\
\text { nonsmokers (B) }\end{array}$ & 4.5 & 2.97 & $<0.10$ \\
\hline No CO, smokers (C) vs. CO, smokers $(\mathrm{H})$ & 1.2 & 0.54 & $>0.10$ \\
\hline $\begin{array}{l}\text { Effect of smoking only } \\
\text { No CO, nonsmokers (A) vs. no CO, smokers (C) } \\
\text { CO or occasional CO, nonsmokers (B) vs. CO }\end{array}$ & 5.9 & 7.34 & $<0.01$ \\
\hline or occasional $\mathrm{CO}$, smokers $(\mathrm{G}+\mathrm{H})$ & 1.5 & 0.82 & $>0.10$ \\
\hline $\begin{array}{l}\text { Effect of } \mathrm{CO} \text { and smoking } \\
\text { No CO, nonsmokers (A) vs. CO, smokers (H) }\end{array}$ & 6.9 & 8.85 & $<0.01$ \\
\hline
\end{tabular}

exposures on one hand and neither of them on the other were compared. For example, the effect of smoking in the groups without occupational $\mathrm{CO}$ exposure did not increase very much when, in addition, $\mathrm{CO}$ exposure was considered. In other words, the additional effect of the other exposure was slight once one exposure was present.

The occurrence of severe chest pain lasting at least $30 \mathrm{~min}$ is shown in table 4 . It was commoner among those exposed to $\mathrm{CO}$, either from smoking or from work. The differences were tested with the Mantel-Haenszel test (15), and the results are shown in table 5 . As can be seen, most of the differences could well have been due to chance.

\section{ECG findings}

The ECG findings were classified as indicative of past myocardial infarction (MC $1.1,1.2+5.1$ or $1.2+5.2$ ) or suggestive of coronary disease (any of $1.2-3$, $4.1-3,5.1-2,6.1-2,7.1-2$, or 7.4 or 8.3 ) (17). The prevalences of these classes, alone and combined, are shown in table 6. No systematic increase of the prevalence of findings as a function of smoking and/or $\mathrm{CO}$ exposure was evident.

We studied the combination of a history of angina or severe chest pain and ECG findings by classifying the workers according to the hierarchical system developed by Pyörälä and his collaborators (17): namely, (a) ECG findings indicative of past infarction (MC 1.1 or $1.2+5.1$ or $1.2+5.2$ ); (b) symptoms (angina and/or severe chest pain) and ECG findings suggesting the presence of CHD (any of $\mathrm{MC}$ $1.2-3,4.1-3,5.1-2,6.1-2,7.1-2,7.4$ or 8.3); (c) symptoms of CHD but no ECG findings; (d) ECG findings indicative of CHD, but no symptoms; (e) neither symptoms nor ECG findings suggestive of CHD. The lowest prevalence of $\mathrm{CHD}$ occurred in nonsmokers without $\mathrm{CO}$ exposure; and the highest, in smokers with $\mathrm{CO}$ exposure. However, the rising trend was exclusively due to angina, and thus no new information was gained from this approach.

Table 4. History of severe chest pain lasting least $30 \mathrm{~min}$, standardized for age.

\begin{tabular}{lrr}
\hline Exposure category & N & $\begin{array}{r}\text { Positive } \\
\text { history } \\
(\% / 0)\end{array}$ \\
\hline Nonsmokers & & \\
No CO exposure (A) & 79 & 6 \\
CO exposure + occasional & 71 & 4 \\
CO exposure (B) & & \\
Exsmokers & 138 & 9 \\
No CO exposure (C) & 68 & 13 \\
Occasional CO exposure (D) & 46 & 6 \\
CO exposure (E) & & \\
Smokers & 236 & 8 \\
No CO exposure (F) & 128 & 11 \\
Occasional CO exposure (G) & 95 & 17 \\
CO exposure (H) & 861 & 9 \\
\hline Total & & \\
\hline
\end{tabular}




\section{Roentgenological findings}

In all, $16 \%$ of the foundry workers had roentgenological findings suggestive of cardiac disorder. The prevalence increased with age and was $3 \%$ in the age group 25 to 34 years and $43 \%$ among those over 55 years. Neither $\mathrm{CO}$ exposure nor smoking related to the roentgenological findings.

\section{DISCUSSION}

Both the ECG and the history of angina obtained with the standardized questionnaire used in this survey are well-docu- mented epidemiologic methods of fairly high validity. Their diagnostic accuracy cannot, of course, be that of a thorough cardiological examination, but in population studies both methods give useful results. The documentation for this statement has been given in many publications $(10,12,16,18,19,20,21,25,26)$.

However, cross-sectional studies of CHD must always be interpreted with caution since the acute nature and high fatality rate of its more severe manifestations result in underestimates of the true occurrence. This is even more so for occupational groups with physically demanding work, because selection becomes an added factor. It is quite conceivable that poor health forces affected persons to leave

Table 5. Significances of reported differences in the frequency of history of severe chest pain. The number of subjects in each group can be found in table 4 .

\begin{tabular}{lllr}
\hline Exposure categories & $\begin{array}{l}\text { Rate } \\
\text { ratio }\end{array}$ & $\chi^{2}{ }_{(1)}$ & P \\
\hline $\begin{array}{l}\text { Effect of CO only } \\
\quad \text { No CO, nonsmokers (A) vs. CO or occasional CO, }\end{array}$ & 0.8 & 0.07 & $>0.10$ \\
$\quad \begin{array}{l}\text { nonsmokers (B) } \\
\text { No CO, smokers (F) vs. CO, smokers (H) }\end{array}$ & 2.3 & 4.78 & $<0.05$ \\
$\begin{array}{l}\text { Effect of smoking only } \\
\quad \text { No CO, nonsmokers (A) vs. no CO, smokers (F) }\end{array}$ & 1.5 & 0.10 & $>0.10$ \\
$\begin{array}{l}\text { CO or occasional CO, nonsmokers (B) vs. CO or } \\
\text { occasional CO, smokers (G+ H) }\end{array}$ & 2.2 & 2.26 & $>0.10$ \\
$\begin{array}{l}\text { Effect of CO and smoking } \\
\text { No CO, nonsmokers (A) vs. CO, smokers (H) }\end{array}$ & 3.5 & 4.08 & $<0.05$ \\
\hline
\end{tabular}

Table 6. Age-standardized prevalences of ECG findings of CHD according to carbon monoxide (CO) exposure and smoking category.

\begin{tabular}{|c|c|c|c|c|}
\hline Exposure category & $\mathrm{N}$ & $\begin{array}{c}\text { Past } \\
\text { myocardial } \\
\text { infarction }(\%)\end{array}$ & $\begin{array}{l}\text { Suggestive } \\
\text { of CHD }(\%)\end{array}$ & $\underset{(\%)}{\text { Combined }}$ \\
\hline \multicolumn{5}{|l|}{ Nonsmokers } \\
\hline $\begin{array}{l}\text { No CO exposure } \\
\text { CO exposure }+ \text { occasional }\end{array}$ & 79 & 0 & 15 & 15 \\
\hline $\begin{array}{l}\text { CO exposure } \\
\text { Exsmokers }\end{array}$ & 71 & 0 & 10 & 10 \\
\hline No CO exposure & 138 & 2 & 10 & 13 \\
\hline Occasional CO exposure & 68 & 0 & 19 & 19 \\
\hline CO exposure & 15 & 0 & 11 & 11 \\
\hline \multicolumn{5}{|l|}{ Smokers } \\
\hline No $\mathrm{CO}$ exposure & 236 & 1 & 15 & 17 \\
\hline Occasional $\mathrm{CO}$ exposure & 128 & 0 & 14 & 14 \\
\hline $\mathrm{CO}$ exposure & 95 & 0 & 16 & 16 \\
\hline Total & 861 & 1 & 14 & 15 \\
\hline
\end{tabular}


work, either voluntarily or because of a doctor's decision. As a result of such selection, fit and healthy workers are usually overrepresented in physically heavy work, as foundry work was before and to some extent still is nowadays.

In order to obtain some quantitative estimate of selection in foundries, we made a questionnaire study of workers who had left this type of work. As described in another communication (14), $14 \%$ of those who had left foundry work after less than 1 year of employment and $7 \%$ of those who had left it after more than 5 years gave a history of hospitalization because of coronary infarction, whereas only $1 \%$ of those still working in the foundries had been hospitalized for the same reason. Other diagnoses of heart conditions showed a similar pattern. As many as $29 \%$ of the former foundry workers with at least 5 years of foundry employment reported health impairment or disability as the reason for quitting foundry work. Thus the prevalences of symptoms and signs of CHD found in this study indeed are underestimates of what would have been the case without any possibility to get away from foundry work. Of course it would have been desirable to include exfoundry workers in the health examination. This action was impossible for practical reasons, however, and thus the information concerning them is based on questionnaires only.

A priori suspicion of the strong selection was the main reason for the decision not to use an external comparison group. Without such a group it is hardly possible to determine whether or not the overall prevalences of angina and ECG findings are higher than "expected." It should be noted, however, that both the prevalences of angina and "coronary" ECGs were surprisingly high. Altogether $14 \%$ of the foundry workers reported angina. In a large survey of the general Finnish population, the age-standardized prevalence was only $3.3 \%$ (17). Such a large difference may at least partly be caused by methodological differences. In this study the history was taken by a self-administered questionnaire, while Pyörälä and his coworkers (17) used interviewers. The average age of workers in our study was slightly higher too. Another factor that should be noted is the high prevalence of cough and chronic bronchitis among the foundry workers (11). It could be postulated that possible chest pain related to this state has been misclassified as angina. Because dust and $\mathrm{CO}$ exposure are not intermixed, and because there was a doseresponse relationship for both $\mathrm{CO}$ exposure and angina and for dust exposure and bronchitis, this explanation is not likely. Besides, chest pain is not very typical of bronchitis. However, since occupational $\mathrm{CO}$ exposure caused clear differences within the foundry worker groups, it is conceivable that its effect was strong enough to increase the overall incidence of angina, at least to some extent. This interpretation is strenghtened by our former experience with exactly the same methodology. For example, the prevalence of angina among 329 paper mill workers with a median age of 50 years and with no known toxic occupational exposure, was $4.9 \%$ only (22).

The high prevalence of ECG changes suggestive of CHD among the foundry workers $(15 \%)$ is more difficult to explain, since no dose-response relationship was evident. The corresponding prevalence was $9.6 \%$ in the study of Pyörälä and his coworkers (17). In this case the methods are more comparable, since the same type of equipment and the same criteria were used and even the technicians who coded the recordings belonged to the group used by Pyörälä and his coworkers. What may lessen the comparability is our failure to arrange a long enough rest before the recording session and the fact that some of the subjects may have had food or a drink recently. The high prevalence of ECG findings among nonsmoking foundry workers indicates that the higher abstinence from smoking before the examination in Pyörälä's study does not explain the difference between our studies. However, it should be stressed that the main purpose of the present survey was to study differences within the group of foundry workers, not between foundry workers and other populations. In this respect the distinction between those exposed to $\mathrm{CO}$ and those not so exposed is the most important.

As already stated in the introduction, there is ample reason to expect a higher 
occurrence of symptoms of $\mathrm{CHD}$ when $\mathrm{CO}$ is present. However, all the excess symptoms found may not be due to $\mathrm{CO}$ alone, since those exposed to $\mathrm{CO}$ are also exposed to heat. In fact, furnacemen and casters are the occupational groups in a foundry that are more exposed to heat than any other group. Thus the confounding effect of heat cannot be controlled with this study design. However, for the sake of simplicity we have used the expression "CO exposure" although the contributory effect of heat has not been ruled out.

The relationship found between a history of angina and $\mathrm{CO}$ exposure, either from ambient air, smoking or both, is compatible with the known effects of $\mathrm{CO}$ (7). From these results it is not, however, possible to conclude whether CHD had been accelerated by $\mathrm{CO}$ exposure or whether it merely provoked symptoms of an existing disease by lowering the oxygen tension of coronary blood. At least the latter mechanism explains a great deal of the excess symptoms, since the carboxyhemoglobin levels were clearly elevated, even among nonsmokers (23).

At least superficially, it seems surprising that the ECG findings did not follow any consistent pattern. If selection were operating, it would primarily affect subjects with angina. Selective mortality could, in principle, explain at least part of the findings. However, as reported elsewhere (13), there was no definite evidence of systematic differences between those exposed to $\mathrm{CO}$ and those not so exposed, even though furnacemen and casters showed a slightly higher mortality than some other categories.

The most likely explanation may thus be that the resting ECG as a method is a poorer discriminant between categories of CHD proneness than the angina questionnaire is. - For example, in the EastWest study of CHD in Finland, there were more "coronary" ECGs in the West although coronary mortality is clearly higher in the East (16). Similarly, in a study of the effect of occupational exposure to carbon disulfide, there was a fourfold excess mortality and a twofold increase in angina in the exposed group as compared to a reference group of paper mill workers, but only a very slight increase in "coronary" ECGs (22). In the case of $\mathrm{CO}$ exposure, it is prob- able that angina occurs particularly when the carboxyhemoglobin concentration is high. When reporting symptoms, the subject may consider a recent period of time, and hence the likelihood for angina to become noted is greater than that for an ischemic ECG finding, which at least partly reflects only the very moment of recording. This systematic difference results from the fact that not all ECGs were recorded during peak exposures, while the report of angina may well reflect these exposure periods. Thus the difference between exposure categories, if there is one with regard to ECG changes, tends to decrease. Furthermore, it may well be that an excercise ECG would have been necessary for revealing $\mathrm{CO}$ induced myocardial ischemia. Such an examination was not possible for practical reasons, however.

The reason for the apparent relationship between blood pressure and $\mathrm{CO}$ exposure is by no means clear. Several studies have shown that both systolic and diastolic pressure rise immediately after smoking (4), and the rise can be demonstrated even 30 min after the smoking of two cigarettes. This occurrence is usually attributed how.ever to the nicotine in the cigarettes rather than to the exposure to CO. Part of the smokers' results in this study can probably be explained by recent smoking, since abstinence could not be achieved. But the differences between the occupational groups (table 1) cannot be thus explained. $\mathrm{CO}$ exposure from the ambient air did seem to have an effect (fig. 1), even though it could not be verified with a high enough probability from a statistical point of view. However, one should remember the association between exposure to heat and exposure to $\mathrm{CO}$. With this in mind, these results do not allow any conclusions as to the cause of the slight elevation of the blood pressure found in groups with CO exposure from smoking and occupation.

\section{ACKNOWLEDGMENTS}

We are indebted to Prof. Kalevi Pyörälä, M.D., for his advice during this study, to Sven Punsar, M.D., for his help with the coding of the Q- and QS-changes and with 
the revision of our manuscript, and to Erkki Järvinen, M.Sc., for the statistical calculations. Matti Wiikeri, M.D., interpreted the radiographs and Ann-Lis Backman, M.D., organized the health examinations. Ms. Outi Marila and Ms. Ritva Halonen coded the ECGs. Ms. Pirjo Fahlström programed the data analysis and Ms. Marja-Liisa Korkala drew the figures.

\section{REFERENCES}

1. ADAMS, J. D., ERICKSON, H. and STONE, H. L. Myocardial metabolism during exposure to carbon monoxide in the conscious dog. J. appl. physiol. 34 (1973) 283-242.

2. ANDERSON, E. W., ADELMAN, R. J., STRAUCH, J. M., FORTUIN, N. J. and KNELSON, J. H. Effect of low-level carbon monoxide exposure on onset and duration of angina pectoris. Ann. intern. med. 79 (1973) 46-50.

3. ANDERSON, E. W., STRAUCH, J., KNELSON, J. and FORTUIN, N. J. Effects of carbon monoxide $(\mathrm{CO})$ on exercise electrocardiogram (ECG) and systolic time intervals (STI). Circulation 44 (1971): suppl. II, $11-135$.

4. ARONOW, W. S., GOLSDMITH, J. R., KERN, J. C., NELSON, W. S., JOHNSON, L. L. and ADAMS, W. Effect of smoking cigarettes on cardiovascular hemodynamics. Arch. environ. health 28 (1974) 330332.

5. ARONOW, W. S., HARRIS, C. N., ISBELL, M. W., ROKOW, S. N. and IMPARATO, B. Effect of freeway travel on angina pectoris. Ann. intern. med. 77 (1972) 669676.

6. ARONOW, W. S. and ISBELL, M. W. Carbon monoxide effect on exercise-induced angina pectoris. Ann. intern. med. 79 (1973) 392-395.

7. ASTRUP, P. and KJELDSEN, $K$. Carbon monoxide, smoking and atherosclerosis. Med. clin. north. amer. 58 (1974) 323-350.

8. ASTRUP, P., KJELDSEN, K. and WANSTRUP, J. Enhancing influence of carbon monoxide in the development of atherosclerosis in cholesterol fed rabbits. $J$. atheroscler. res. 7 (1967) 343-354.

9. BIRNSTINGL, M., HAWKINS, L. and MC EVEN, T. Experimental atherosclerosis during chronic exposure to carbon monoxide. Eur. surg. res. 2 (1970) 92-93.

10. BLACKBURN, H. Electrocardiographic classification for population comparisons: The Minnesota code. $J$. electrocardiol. 2 (1969) 5 .

11. KÄRÄVÄ, R., HERNBERG, S., KOSKELA, R.-S. and LUOMA, K. Prevalence of pneumoconiosis and chronic bronchitis in foundry workers. Scand. j. work environ. \& health 2 (1976): suppl. 1, 64-72.

12. KEYS, A., ARVANIS, C., BLACKBURN,
H. W., VON BUCHEM, F. S. B., BUZINA, R., DJORDJEVIĆ, B. S., DONTAS, A. S., FIDANZA, F., KARVONEN, M. J., KIMURA, N., LEKOS, D., MONTI, M., PUDDU, V. and TAYLOR, H. L. Epidemiological studies related to coronary heart disease: Characteristics of men aged $40-59$ in seven countries. Acta med. scand. (1967): suppl. 460.

13. KOSKELA, R.-S., HERNBERG, S., KÄRÄVÄ, R., JÄRVINEN, E. and NURMINEN, M. A mortality study of foundry workers. Scand. j. work environ. \& health 2 (1976): suppl. 1, 73-89.

14. KOSKELA, R.-S., LUOMA, K. and HERNBERG, S. Turnover and health selection among foundry workers. Scand. j. work environ. \& health 2 (1976): suppl. 1, 90105.

15. MANTEL, N. and HAENSZEL, W. Statistical aspects of the analysis of data from retrospective studies of disease. J. natl. cancer inst. 22 (1959) 719-748.

16. PUNSAR, S. and KARVONEN, M. J. Angina pectoris and ECG abnormalities in relation to prognosis of coronary heart disease in population studies in Finland. Adv. cardiol. 8 (1973) 148-161.

17. PYORÄLÄ, K., PUNSAR, S., REUNANEN, A., HEINONEN, O. P., PURO, $\mathrm{K}$. and AROMAA, A. Kansaneläkelaitoksen sepelvaltimotutkimus: Rintakipuoireiden ja EKGlöydösten esiintyvyys alkututkimuksessa [Social Insurance Institution's coronary heart disease study: Prevalence of chest pain symptoms and ECG findings in nine Finnish population groups] (Kansaneläkelaitoksen julkaisuja, sarja AL: 1/1974). Sosiaaliturvan tutkimuslaitos, Helsinki. (English summary)

18. REID, D. D., CORNFIELD, J., MARKUSH, R. E., SEIGEL, P., PEDERSEN, E. and HAENSZEL, W. Studies of disease among migrants and native populations in Great Britain, Norway and The United States: III. Prevalence of cardiorespiratory symptoms among migrants and native born in the United States. Natl. cancer inst. monogr. (1966): 19, 321.

19. ROSE, G. A. Predicating coronary heart disease from minor symptoms and electrocardiographic findings. $\mathrm{Br}$. j. prev. soc. med. 25 (1971) 94.

20. ROSE, G. A., AHMETELI, M., CHECCACCI L., FIDANZA, F., GLAZUNOV, I., DE HAAS, J., HORSTMAN, P., KORNITZER, M. D., MELONI, C., MENOTTI, A., SANDER SAUDE, D., DE SOTO-HARTGRINK, M. K., PISA, $Z$. and THOMSEN, B. Ischemic heart disease in middle-aged men: Prevalence comparisons in Europe. Bull. WHO 38 (1968) 885.

21. ROSE, G. A. and BLACKBURN, H. Cardiovascular survey methods. World Health Organization, Geneva 1968.

22. TOLONEN, M., HERNBERG, S. and NURMINEN, M. A follow-up study of coronary heart disease in viscose rayon workers exposed to carbon disulphide. $B r . j$. ind. med. 32 (1975) $1-10$. 
23. VIRTAMO, $\mathbf{M}$. and TOSSAVAINEN, $\mathbf{A}$. Carbon monoxide in foundry air. Scand. j. work environ. \& health 2 (1976): suppl. 1, $37-41$.

24. WEBSTER, W. S., CLARKSON, T. B. and LOFLAND, H. B. Carbon monoxide-aggravated atherosclerosis in the squirrel monkey. Exper. mol. pathol. 13 (1970) 3650 .
25. WELBORN, T. A., CUMPSTON, C. N., CULLEN, K. J., CURNOW, D. H., MC CALL, M. C. and STENHOUSE, N. S. The prevalence of coronary heart disease associated factors in an Australian rural community. Am. j. epidemiol. 89 (1968) 521.

26. ZEINER-HENRIKSEN, T. Cardiovascular disease, symptoms in Norway - A study of prevalence and mortality follow-up. J. chronic dis. 24 (1971) 553. 